\title{
Taxation and Market Power
}

\author{
* Max Planck Institute for Intellectual Property, \\ Competition and Tax Law and WZB \\ ** Max Planck Institute for Intellectual Property, \\ Competition and Tax Law \\ *** Tilburg University
}

SP || $2010-07$

May 2010 
Kai A. Konrad, Florian Morath, Wieland Müller, Taxation and Market Power, Discussion Paper SP II 2010 - 07, Wissenschaftszentrum Berlin, 2010.

Wissenschaftszentrum Berlin für Sozialforschung $\mathrm{gGmbH}$, Reichpietschufer 50, 10785 Berlin, Germany, Tel. (030) 25491 - 0 Internet: www.wzb.eu 


\section{ABSTRACT}

\section{Taxation and Market Power}

by Kai A. Konrad, Florian Morath and Wieland Müller *

We analyze the incidence and welfare effects of unit sales taxes in experimental monopoly and Bertrand markets. We find, in line with economic theory, that firms with no market power are able to shift a high share of a tax burden on to consumers, independent of whether buyers are automated or human players. In monopoly markets, a monopolist bears a large share of the burden of a tax increase. With human buyers, however, this share is smaller than with automated buyers as the presence of human buyers constrains the pricing behavior of a monopolist.

Keywords: Tax incidence, monopoly, Bertrand competition, experiment

JEL classification: H22, L12, L13, C72, C92

\section{ZUSAMMENFASSUNG}

\section{Besteuerung und Marktmacht}

Dieser Artikel untersucht Inzidenz- und Wohlfahrtseffekte einer Mengensteuer in experimentellen Monopol- und Bertrand-Märkten. Im Einklang mit der ökonomischen Theorie sind Firmen ohne Marktmacht in der Lage, einen großen Anteil der Last einer Steuererhöhung an die Konsumenten weiterzugeben. Dies gilt unabhängig davon, ob die Käufer simuliert sind oder die Kaufentscheidungen durch reale Käufer getroffen werden. In Monopolmärkten trägt der Monopolist einen großen Anteil der Last einer Steuererhöhung. Werden die Kaufentscheidungen durch reale Käufer getroffen, ist dieser Anteil jedoch kleiner als mit simulierten Käufern, da reale Käufer im Experiment das Preissetzungsverhalten des Monopolisten einschränken.

\footnotetext{
Financial support of LMUexcellent is gratefully acknowledged. For providing laboratory resources we kindly thank MELESSA of the University of Munich. The third author acknowledges financial help from the Netherlands Organisation for Scientific Research (NWO) through a VIDI grant.
} 


\section{Introduction}

The economic incidence effects of taxation in the context of markets is a core issue in public finance. Who bears the economic burden of a specific tax has implications for policy-makers and for the political economy of taxation. The analysis of the tax-induced economic burden as a function of market conditions and market power has, hence, attracted considerable attention in the theory of taxation. ${ }^{1}$ Yet there is a discrepancy between the predictions of standard economic theory and the public opinion on the impact of market power on the burden of a tax (as illustrated below). Moreover, empirical studies of tax incidence in specific markets have lead to mixed results. In this paper we provide experimental evidence on the role of market power for the incidence effects and welfare effects of taxation. We compare the incidence effects of a unit sales tax for the case of monopoly with Bertrand competition, allowing for two different regimes regarding consumers' decision making.

Textbook theory suggests that monopoly firms typically bear a large share of the burden of an increase in sales taxes, whereas firms with little or no market power can often shift all of the additional tax burden to the buyers (Myles 1995, 358-363). Intuitively, Bertrand competition between firms without market power should make prices fall to the point of zero profits. Thus, with Bertrand competition for homogenous products, firms cannot bear the burden of an additional tax. If their unit cost of production is increased by a tax, either they can shift the burden of this tax to the buyers, or they must exit the market (Fullerton and Metcalf, 2002, p. 1824). In contrast, monopolists choose monopoly prices in the absence of taxation, maximizing their monopoly profits. If they have to pay a unit tax on sales, the monopoly profit can potentially serve as a buffer that enables them to absorb this cost shock. The monopolist may adjust the price in line with the marginal-cost-equals-marginal-revenue calculation. Depending on the demand and the marginal cost curve, this may cause an increase in the monopoly price by less or more than the amount of the tax, and the cost increase will hurt the monopolist strongly (Bishop 1968). ${ }^{2}$

The incidence of a specific tax has also become the focus of much empirical research. Studies

\footnotetext{
${ }^{1}$ See Fullerton and Metcalf (2002) for a detailed survey.

${ }^{2}$ Theoretical considerations are less straightforward for imperfect competition with more than one firm. Seade (1985) and Stern (1987) showed that firms may shift more than the total increase in their unit costs onwards to customers in different frameworks with imperfect competition. Collusion and its break-down, entry and exit decisions, combined with a non-linear cost structure and specificities of the demand function may play a role. Hamilton (2008) highlights the importance of multiproduct markets.
} 
of specific markets find a large variety of pass-through rates of taxes both for Bertrand competition and for imperfect competition. ${ }^{3}$ Moreover, the question of pass-through of cost increases - whether tax induced or not-is a key question for practitioners in capital markets, and the perceptions articulated by practitioners and non-economists are often in contrast with the theory predictions of tax incidence theory. The financial newspaper Financial Times Deutschland, citing a UBS research paper, analyzes investment strategies in times of cost inflation. The author of the article argues that investors should seek firms with much market power. Global equity research at UBS by Nelson (2008) recommends the purchase of "price makers" to deal with cost inflation, and a paper about pricing power by Exane BNP Paribas (p.11) states that they expect firms with "genuine pricing power" to outperform the market in times with cost inflation. They identify three channels for pricing power to help in an environment with increasing cost. One of these is a type of monopoly power (see page 11):

Brands are used by companies to allow them to charge premium prices. When prices rise, customer loyalty means that there will be a limited impact on demand. Even if a lower-price product is available, especially if the product does not represent a significant proportion of a consumer budget, the brand-loyal customer will pay up. This means that it may be possible to preserve margins in an inflationary environment.

This perception may be contrasted with the theory's point of view: monopolists should have already used an existing range for price increases, rather than wait for a cost shock before using the available opportunities for profit maximization.

\footnotetext{
${ }^{3}$ Seade (1985) gave as motivation for his theoretical analysis the successful cost-shifting by large multinational oil companies during the first oil crisis. Kim and Cotterill (2008) find pass-through rates of 21-31 percent under collusion and between 73 and 103 percent under Bertrand competition for a market with differentiated brands. Studies by Devereux and Lanot (2003) and Chouinard and Perloff (2004) show a pass-through in the interior between 0 and 100 percent for mortgages and gasoline taxes, respectively. Poterba (1996) considers the markets for clothing, essentially confirming the theoretical predictions about a 100 percent pass-through of taxes in competitive markets. Besley and Rosen (1999) consider prices in different locations which apply different sales taxes and find that, in line with the competitive markets theory, the higher taxes are fully passed through. For some products, however, they find prices that are substantially higher than for a full pass-through. For instance, for alcohol taxes, pass through rates above 100 percent occur more frequently. Young and Bielinska-Kwapisz (2002) finds evidence suggesting that excise taxes on alcohol increase the price of alcohol by three times the amount of the excise tax increase. Kenkel (2005) shows that increases in per-unit taxes on alcoholic beverages were more than fully passed through to consumers in Alaska and surveys other studies for several different markets.
} 
The divergence between practitioners' perceptions and theory predictions, and the heterogenous empirical results together with the multiplicity of different possible factors causing these pass-through rates highlight the importance of studying the tax incidence effect of market power in an experimental framework that makes it possible to isolate the effect of market power which pertains to the theoretical considerations. For this purpose we analyze the equilibrium reactions to a unit sales-tax increase for both a monopoly market and for a Bertrand market for homogenous products. We derive theory predictions for the specific market framework and consider which of the theory predictions is in line with the observed behavior in the experiment. In order to be able to distinguish between pure supply-side effects (monopoly versus competition) and the role of strategic interaction between buyers and sellers (automated buyers versus truly human decisionmakers) we consider two different demand regimes. For one market regime firms know that they sell their goods to a market with automated demand that emulates customers behaving in line with textbook economics. In this context, sellers do not face any uncertainty about the buyers' reactions to market prices. We find that Bertrand competition in the experimental market is in perfect conformity with textbook economics: Bertrand competitors fully pass through the tax increase to their customers. For the monopoly equilibrium with automated demand, the empirical outcome is also close to the textbook prediction. We then consider the same monopoly and Bertrand setups with buyers who are not automated but real human customers whose purchasing decisions may, but need not necessarily, coincide with the predictions of standard consumer theory. We find that Bertrand competitors who are dealing with (and know they are dealing with) real customers are also successful in passing through their full tax-induced cost increases to the buyers, similar to the results with automated demand. Major deviations from the textbook predictions occur for the monopoly with real human buyers. Monopolists who know they offer their goods to real players do not achieve the monopoly price as an equilibrium outcome even before the tax increase. Also not all buyers follow their pure material interests. Some refuse to buy if the price is too close to their (laboratory-induced) monetary valuation. The increase in the monopolist's cost increases the equilibrium price; however, the increase is less than half the size of the tax-induced increase in the monopolist's cost. Hence, the monopolist is able to shift a smaller share of the cost increase onward to the buyers, somewhat in contrast to the predictions of textbook monopoly pricing. However, even in the setting with individual buyers as decision makers on the demand side, the monopolist bears a large share of the tax burden. 
Few earlier studies considered taxes in experimental markets ${ }^{4}$, and even fewer experiments on tax incidence have been carried out. None of these studies considered the role of market power. Kerschbamer and Kirchsteiger (2000), Kachelmeier et al. (1994), Borck et al. (2002), Riedl and Tyran (2005) and Ruffle (2005) study the relationship between statutory and economic incidence: whether the statutory rule about who physically delivers the tax to the tax authorities affects the incidence of the tax. All of these studies keep the market institution and the nature of demand constant. Quirmbach et al. (1996), addressing the incidence of corporate taxation in a simple Harberger-type general equilibrium game, find that capital owners are able to shift some share of the burden of capital taxation. However, their experiment does not make it possible to address the relationship between market power and tax incidence. In contrast, we ask what the role of market power is for tax shifting and for the size of the excess burden, and how this result depends on whether the demand side consists of real buyers as decision-makers. This fundamental role of market structure for tax incidence and the excess burden of taxation has received surprisingly little attention in experimental work.

We use a simple framework that enables us to make strong and straightforward predictions about tax incidence. This framework is described in section 2. Testable hypotheses about the incidence and welfare properties of the unit sales tax as a function of market structure are developed in section 3. Section 4 describes the experimental design and explains these choices, discussing how our experimental design relates to the experimental markets literature, as our analysis builds upon experience on experimental market games. ${ }^{5}$ Section 5 contains the experimental results on tax incidence and welfare and section 6 concludes.

\section{Tax incidence with block demand}

We consider a market for a single homogeneous good. The good is produced by $n$ firms, where $n=1$ refers to the monopoly case and $n=4$ involves competition, and the good is sold to $m=4$ buyers. Each firm can produce units of this good for a constant unit cost equal to $c=6.5$. In addition, for each unit sold, the firm needs to pay a unit sales tax equal to $t \in\{2,6\}$, causing tax-inclusive total

\footnotetext{
${ }^{4}$ Incentive effects of taxes have been studied in the context of labour leisure choices (see, e.g., Sillamaa 1999, Sutter and Weck-Hannemann 2003, Ortona et al. 2008, Levy-Garboua et al. 2009). The role of taxes for the performance of markets has also received some attention. Bloomfield et al. (2009) analyze the role of transaction taxes for trade in financial markets with informed and noise traders, and find that they affect both types of traders similarly.

${ }^{5}$ The literature is surveyed, e.g., by Plott (1989) and Holt (1995).
} 
unit cost of production of $c+t$. Each firm $i$ chooses a price $p_{i} \in \mathbb{N}$. We consider a finite grid of prices that maps the finite grid of prices that exists in real markets, due to currency indivisibilities. It also has the practical benefit of making the pricing equilibrium unique, and avoids open-set problems regarding optimal choice. ${ }^{6}$ At price $p_{i}$, the firm $i$ is willing to produce and sell as many units as are demanded. A simple price revelation mechanism matches firms and buyers together: the market mechanism identifies the lowest offer price and announces this offer price to the buyers. Buyers observe the lowest offer price and decide whether to purchase one unit of the homogeneous good at this price. A buyer either purchases exactly one unit, or does not buy at all. All buyers forward the units they purchase to the laboratory and receive $q=24.5$ laboratory currency units per unit of the good. We call this price the (laboratory-induced) monetary valuation. If several firms offer the good at the same lowest price, the number of units demanded is assumed to be allocated evenly among the sellers.

If all sellers and buyers maximize their monetary payoffs, this game has a unique Nash equilibrium for each of the different parameter values $(n, t) \in\{(1,2),(1,6),(4,2),(4,6)\}$. For $n=1$ the seller is a monopolist facing a block demand of four units. The profit-maximizing integer price $p_{1}$ is 24 , yielding a profit that is equal to $\pi_{M}=64$ for $t=2$ and $\pi_{M}=48$ for $t=6$. Consumer rent for each buyer is equal to 0.5 for both values of the unit tax. This market equilibrium is efficient. The tax does not distort the allocation, and it does not generate an excess burden in the market. Further, the higher tax causes an increase in the tax revenue from $T R_{(t=2)}=8$ to $T R_{(t=6)}=24$. At the same time, the monopoly profit falls from 64 to 48 , a decrease of precisely the same size as the increase in the tax revenue. This determines the tax incidence: the increase in the sales tax is fully borne by the monopolist.

Turning to the cases of Bertrand competition, $(n, t) \in\{(4,2),(4,6)\}$, the Nash equilibrium in prices has $p_{i}=p=9$ for all $i=1,2,3,4$ if $t=2$, and $p_{i}=p=13$ if $t=6$. As a result, each buyer purchases one unit and each firm sells one unit at the equilibrium price. Each seller makes a profit equal to 0.5 for both levels of taxes. Each buyer has a consumer rent of $24.5-p$, which is equal to 15.5 for $t=2$ and equal to 11.5 for $t=6$. Accordingly, for the Bertrand market the loss in the aggregate sum of producer and consumer rents is again equal to the tax revenue from the increased sales tax. Moreover, the tax is fully borne by the buyers. Bertrand competitors can fully shift the burden of taxes onwards to the buyers.

These results illustrate a cornerstone of partial analytic theory of tax incidence: with block

\footnotetext{
${ }^{6}$ For a discussion of the role of a smallest unit for Bertrand equilibrium see Hehenkamp and Leininger (1999).
} 
demand, a monopolist bears the burden of higher taxes, whereas sellers with no market power can pass this burden through to their customers. The experiments can reveal whether these fundamental results do materialize, and which additional effects are present. One set of treatments compares monopoly and Bertrand competition, isolating supply effects by replacing real demand by automated demand, which makes the demand behavior for different prices fully predictable for suppliers. A second set of treatments adds demand decisions by real individuals. This introduces a potentially important element of strategic uncertainty. Sellers must form expectations about purchase decisions of buyers. Sellers know that buyers are paid 24.5 for each unit of the good that they purchase. However, whether buyers actually buy at a given smallest observed price is another matter. An implicit assumption in the textbook analysis is that buyers purchase if and only if their (externally induced) monetary valuation of the good is higher than the offer price. If real individuals make the purchasing decisions, their actual net benefit from the purchase decision may deviate from the externally induced monetary valuation. Assume, for instance, that buyers consider the monopoly situation similar to an ultimatum game: by suggesting a price, the monopolist offers the buyer a piece of the pie. The buyer then has to accept or refuse this offer. The theory of ultimatum games generated a wealth of evidence for why we should not expect an outcome in which the monopolist charges 24 , but a smaller price, and why some buyers may reject prices of 24 or lower. Many of these theories fit well with the idea that buyers are heterogenous in their boycott behavior. Let, for instance, $F(p)$ be the share of buyers who accept all prices lower than or equal to $p$. The monopolist then simply faces an uncertain demand function, where the size of the demand at a given price is $m F(p)$, where $m$ is the number of units sold.

\section{$3 \quad$ Theoretical predictions}

The hypotheses focus on how market power affects the ability of sellers to shift the tax burden onwards to buyers, and whether human decision-making on the buyers' side plays a role. We expect the strategic uncertainty generated by human buyers' decision-making to play a key role. The first conjecture, stated as a testable hypothesis, addresses the case with automated demand:

Hypothesis 1 In the absence of strategic demand uncertainty (i.e., with automated demand), Bertrand competitors can fully pass on the burden of a tax increase to the buyers. A monopolist cannot pass on the burden of taxation to its buyers. The monopolist bears the full burden of an additional tax. 
Human buyers may, but need not purchase a good (i.e., 'boycott') if the offer price is below their benefit in monetary terms if they do purchase the good. We expect buyers to be more likely to boycott if

(a) the monetary rent they sacrifice by their refusal to purchase is small, or

(b) the price offer they face gives them a small share in the overall rent that has to be shared between the seller(s) and the buyers.

These conjectures are in line with a number of behavioral considerations (fairness, inequality aversion, an educational mission to punish players who deviate from socially acceptable equity norms, a simple heuristic suggesting not to accept deals that are too asymmetric, etc.).

We use (a) and (b) to form hypotheses about the two treatments with real (human) buyers. Consider first Bertrand competition. In the textbook equilibrium the market price drops to the price closest to the sellers' tax-inclusive costs. A seller's fear of possible boycott cannot reasonably drive down the price further than that. Boycott considerations should therefore not play a role for Bertrand competition. The empirical Bertrand game outcomes for automated and human buyers should not systematically differ. Bertrand competitors should be able to shift the burden of taxes onwards to the buyers also if these are human buyers. For the monopoly case, the boycott option of human buyers can make a difference. The monopolist charges a price close to the buyers' monetary valuation for the case of automated buyers. This leaves almost no rent for a buyer if he purchases at this price, and it leads to a very uneven distribution of the total rent of the transaction, with almost all rent appropriated by the monopolist. The motivations in (a) and (b) for boycott may both be relevant and cause strategic uncertainty: this may induce monopolists to charge less than the price that is closest to the buyers' monetary valuation. An increase in the tax may then have an impact on the pricing behavior, as it affects the distribution of rents. The testable hypotheses resulting from this are:

Hypothesis 2 With demand choices made by real individuals, Bertrand competitors can pass on the entire burden of a tax increase. A monopolist can pass on a significant part of the tax increase to the buyers.

Boycott is a possible source of inefficiency: if a purchase does not take place, the value between production cost and the buyers' induced monetary valuation will be lost. If Hypothesis 2 holds, buyers' boycott does not play a big role in Bertrand markets and the efficiency of Bertrand markets is high even with real buyers. Boycott may become an issue in the monopoly case. We 
expect:

Hypothesis 3 For real buyers in a monopoly market, the observed demand differs from block demand and is downward-sloping for a range of prices that is smaller than the monetary gross benefit from purchasing the good.

We can use the observed demand decisions in the experiment to estimate this (potentially) downward-sloping demand pattern and ask whether, and to what extent, the monopolist's pricing pattern is a profit-maximizing reply to this demand pattern. In a purely static framework, a buyer knows $c+t$ and the monetary valuation $r$. Facing a market price offer of $p$, the buyer must decide whether to purchase a unit or to boycott. Given the considerations on (a) and (b) above, buyers may have a threshold price, and different buyers may purchase if and only if the price is not higher than their respective threshold price. This threshold need not be the same for all buyers. This generates a cumulative distribution function $F(p)$ describing the share of buyers purchasing a unit of the good for each possible offer price. If the monopolist knows the probability distribution $F(p)$ and wishes to maximize his monetary payoff, his expected payoff is equal to

$$
(p-c-t) F(p) m
$$

where $m$ is the number of buyers. The strategic multi-period problem is potentially more complicated. The monopolist may have a prior belief about $F(p)$. The monopolist may also try and experiment in order to find out about what types of buyers he was matched with. The buyers may, therefore, act strategically when making their choices in early rounds. This latter motivation for each single buyer is absent if the number of buyers is large, because each buyer then considers his own influence on the probability update of the monopolist as insignificant. Making the somewhat strong assumption here that four buyers are a big number and each of them feels atomistic, this eliminates the incentive of strategic purchasing behavior and simplifies the problem. The monopolist can then use the buyers' decisions in the first $N-1$ rounds to find an estimate about $F(p)$ and choose a price in the last round that maximizes the expected profit that emerges from this estimate about $F(p)$. We consider the following

Hypothesis 4 In the last round the monopolist chooses $p$ to maximize $(p-c-t) F(p) m$, where $F(p)$ is the monopolist's posterior belief about the share of buyers who purchase the good if the price is not higher than $p$, and where the monopolist uses buying decisions in previous rounds to update his beliefs about $F(p)$. 
The boycott behavior of real buyers and pricing of firms has welfare implications. If the conjectures about Bertrand competition are correct, then the imposition of a unit sales tax does not generate an excess burden in a framework with block demand. For the monopoly case, in the absence of strategic buyer uncertainty, the monopolist should earn a rent equal to $m \times(24-c-t)$ and the sum of buyers' monetary payoffs should be equal to $0.5 \times m$. Due to buyers' boycott and monopolists' pricing choices, the expected payoffs are $F(p) m(p-c-t)$, and the monopolist chooses the $p(t)$ maximizing this expression. A buyer's monetary payoff is $F(p)(24.5-p)$ for this profitmaximizing price. The tax revenue is $t F(p) m$. The excess burden (defined as the total sacrifice in monetary payoffs of the seller, the buyers and the government compared to transactions that maximize this monetary sum) can be described as

$$
[1-F(p(t))] m(24.5-c)
$$

Hypothesis 5 The monopoly outcome with real buyers is characterized by a strictly positive excess burden. The Bertrand markets and the monopoly with automated demand are efficient.

It is interesting to ask whether the welfare loss in the monopoly case with real buyers increases or decreases if the tax rate is higher. With boycott considerations being absent, both tax rates $t \in\{2,6\}$ should yield an efficient outcome in which four units are sold. With boycott considerations several countervailing effects can be at work. First, if the unit sales tax is increased, this may change the maximum price that a buyer may be willing to accept. One natural conjecture would be that the observed increase in the seller's tax-inclusive unit cost may make a buyer more inclined to accept a given price. As this may be conjectured by the monopolists as well, they may also charge a higher price in this case, leaving it open whether the increase in the tax causes an increase or a decrease in transactions. Second, the increase in the unit tax narrows the range in which possible mutually beneficial transactions can take place from the set of prices $\{9,10, . ., 24\}$ to the set $\{13,14, \ldots, 24\}$, which in turn may reduce the boycott problem. To see this, consider the extreme with $t=17$. For this tax, the set of prices yielding a positive monetary payoff for the monopolist and for the buyers has only one element: $p=24$. We would expect that, for $t=17$, buyers do not boycott at a price of $p=24$. Hence, narrowing down the range of mutually profitable transaction prices may enhance efficiency. There may also be a negative effect of narrowing down the range of mutually profitable transaction prices. As suggested by the theory of Myerson and Satterthwaite (1983), efficiency of bargaining under mutually asymmetric information can be taken for granted only if a seller's range of possible reservation prices and the buyer's range of possible 
willingness to pay are sufficiently disjoint (in a sense that need not be made more precise here). The increase in the seller's reservation price narrows the gap between the monetary parts of the seller's reservation price and buyers' monetary valuation. The actual reservation prices of the seller and the buyers may be obtained from these monetary values by adding a random component that reflects, for instance, their willingness to sanction violations of their (unobserved) norms. Each buyer's true reservation price becomes a random variable. If this random variable is not altered by the increase in the seller's actual tax including production cost, bargaining theory suggests that the narrowing of the range of mutually profitable prices may reduce the ex-post efficiency of transactions. However, the rent that buyers demand for refraining from boycott need not be independent of $m-(c+t)$, making the direction of this effect less clear-cut.

Quantitatively, the change in the excess burden, or welfare loss, is

$$
[F(p(2))-F(p(6))] m(24.5-c)
$$

the change in the total burden for the monopolist is

$$
F(p(2)) m(p(2)-c-2)-F(p(6)) m(p(6)-c-6)
$$

and the change in the burden for the buyers is

$$
F(p(2)) m(24.5-p(2))-F(p(6)) m(24.5-p(6)) .
$$

As discussed, a theoretical prediction about the sign of these terms cannot be made, due to the conjectures about several partially countervailing effects.

We now describe the experiment and then turn to the results, contrasting the outcomes with the theoretical considerations.

\section{Experimental design, procedures, and related literature}

Experimental design and procedures. Our experiment is based on a $2 \times 2$ factorial design, varying market power of firms on the supply side (monopoly vs. oligopoly), and distinguishing between simulated and real (that is, human) buyers on the demand side of a market. All sellers in our treatments are human decision -makers. We refer to the four treatments as follows. The monopoly treatment with simulated buyers is called "MonSim," whereas the monopoly treatment with real buyers is called "MonReal." Similarly, the oligopoly treatment with Bertrand price 
competition and simulated demand is called "BERTSim," whereas the Bertrand market with real buyers is called "BERTREAL."

In the instructions, ${ }^{7}$ we used a non-neutral frame, with firms being referred to as "sellers" and consumers being referred to as "buyers." Subjects were informed that the experiment would consist of two parts and that they would first only be informed about the rules in the first part of the experiment. Only after completion of the first part were subjects informed about the rules of the second part. Each part of the experiment consisted of 10 decision rounds. Earnings in the experiment were measured in "points" which, at the end of the experiment, were converted into real money (see below). In the following we describe the setting in each of the four treatments.

MonSim Treatment : On the supply side, there is one monopolist seller who offers to sell up to four units of a good in the market. On the demand side, there are four simulated buyers, each willing to buy one unit of the good and who have a monetary valuation for this unit of 24.5. At the beginning of each period the seller chooses a price (a non-negative integer) at which he would be willing to satisfy the demand of up to 4 units of the good. Sellers were informed that each of the four simulated buyers per market would then (independently) buy a unit of the good if and only if the price is not higher than 24.5. At the end of a period, the monopolist was informed about the number of units bought and about his own profit.

MonReal Treatment: The supply side is as in the MonSim treatment. On the demand side, there are four real buyers who can each buy one unit of the good and have an (induced) monetary valuation for this unit of 24.5, which was publicly known. After the monopolist made his decision about the price (at which he would be willing to satisfy the demand of up to 4 units of the good), buyers were informed about this price and then asked to independently and simultaneously make their purchase decision. At the end of a period, the monopolist was informed about the number of units bought (without any indication of the identity of buyers who bought or did not buy a unit) and about own profits. Buyers were informed about their own profit but not about the number of units sold by the monopolist.

BertSim Treatment: On the demand side, there are four sellers in each market who can each sell up to four units of the good in the market. ${ }^{8}$ Sellers were informed about the four simulated buyers and how these simulated buyers would make their purchase decision given the market price.

\footnotetext{
${ }^{7}$ The experiment was administered in German. A complete set of translated instructions can be found in the Appendix.

${ }^{8}$ We use four sellers, as Dufwenberg and Gneezy (2000) found that the Bertrand solution predicts behavior well if there are three or more firms, whereas two sellers are more prone to collude.
} 
(Simulated buyers "acted" as described for the MonSim treatment.) At the beginning of each period, each of the four sellers was asked to independently and simultaneously choose a price at which he would be willing to satisfy the demand of up to 4 units of the good. Sellers knew that the lowest of the four chosen prices would be selected and passed on to buyers who would then make their purchase decisions. Subjects were informed that in case of more than one seller choosing the lowest price, the units that would be sold at this price would be equally divided among the sellers who chose the lowest price. At the end of a period, the sellers were informed about the lowest chosen price, the own number of units sold, and own profit. ${ }^{9}$

BertReal Treatment: Regarding sellers (buyers), the setting was as in the BerTSim treatment (MONREAL).

Each seller in each of the treatments had production costs of 6.5 points per unit sold in all periods of the experiment. Additionally, sellers had to pay a unit tax for each unit sold. This unit tax was equal to 2 points in the first phase of the experiment (10 periods). This feature was part of the instructions. In the second phase of the experiment, which also consisted of 10 periods, this unit tax was increased to 6 points per unit sold. After completion of the first phase of the experiment, a window appeared on subjects' screens informing them that the only change would be that sellers now had to pay a unit tax of 6 points per unit sold instead of 2 points and that all other rules would be the same as in the first phase of the experiment.

The experiment was programmed and conducted with the experiment software z-Tree (Fischbacher 2007) and run at the MELESSA lab of the University of Munich. The subjects were students from more than 40 different fields of study (112 subjects in total). ${ }^{10}$ Each subject received an endowment of 25 points at the beginning of the experiment. This was done to cover possible losses. Subjects were informed that the sum of their earnings in points during the experiment plus their initial endowment would be converted into real money at the end of the experiment. In an effort to balance payments across treatments, we used an exchange rate of points to euros of, respectively, 200:1 (MonSim treatment), 25:1 (MonReal treatment), and 10:1 (BertSim and BertReal treatments). Table 1 summarizes basic information about the design.

\footnotetext{
${ }^{9}$ Only the lowest price, not the distribution of prices was reported to other players in order to make collusion more difficult, and, hence, come closer to a framework with perfect competition. Dufwenberg and Gneezy (2002) found that reporting of higher prices may facilitate collusion.

${ }^{10}$ The participants were recruited using the software ORSEE (Greiner 2004).
} 


\begin{tabular}{ccc}
\hline \hline & Simulated Buyers & Real (Human) Buyers \\
"MonSim" & "MonREAL" \\
Monopoly & 1 seller, 4 simulated buyers & 1 seller, 4 human buyers \\
& Number of markets: 10 & Number of markets: 6 \\
Number of subjects: 10 & Number of subjects: $30(=6 \times 5)$ \\
"BeRTSiM" & "BeRTREAL" \\
& 4 sellers, 4 simulated buyers & 4 sellers, 4 human buyers \\
& Number of markets: 6 & Number of markets: 6 \\
\hline \hline
\end{tabular}

Table 1: Overview of the 2 by 2 factorial design

Related experimental literature. Our analysis builds on a solid stock of knowledge from the literature on experimental market games, which cannot be surveyed here. Each of our treatments borrows from these insights, which also means that the setup of most of the respective experimental markets which we consider has been used in one or several other experiments in the context of other research questions.

Since sellers in our experiments make take-it-or-leave-it price offers to buyers, results on experimental posted-offer trading institutions are relevant. Monopoly markets using this institution are known to achieve prices "well above competitive levels, but on average, profits are significantly below theoretical monopoly levels." (Holt, 1995, p.381). A difference is that, next to the offer price, sellers in posted-offer markets typically also indicate the number of units they are willing to sell. We eliminated this feature in order to come closer to the textbook framework of a price-setting monopolist. The monopoly game we consider is also structurally related to the ultimatum game. From this literature (see, e.g., Güth, 1995, or Roth, 1995) it is known that proposers often propose the equal split, and that the probability of rejection by responders increases as offers decrease. These results shaped our hypotheses as regards the MONREAL treatment.

There is also considerable evidence from experimental Bertrand markets. Experimental results in homogeneous markets show that while market prices stay above the competitive level in duopoly, they quickly converge to the competitive level when there are three or more firms in the market (see, e.g., Fouraker and Siegel, 1963, and Dufwenberg and Gneezy, 2002). Also, collusion among sellers is more difficult if only the lowest posted price is announced. For these reasons, 
we chose four sellers and posted only the lowest offer price. Tyran and Engelmann (2005) study consumer boycotts in a posted-offer market. ${ }^{11}$ They study a market with three human sellers and five human buyers and ask whether a referendum among buyers about a boycott can make boycott a more effective kind of countervailing buyer power. They also study the role of a production cost increase for the effectiveness of boycott in treatments without a referendum and with a (individually non-binding) referendum. Although their research question is a completely different one, their base treatment (without a referendum) can be seen almost as the blueprint for our BERTREAL treatment, except for one difference: their suppliers have the option of withholding or limiting their supply (at a given price). We turned the suppliers into perfect Bertrand competitors by removing their option of limiting or withholding supply. This choice removes part of the power to threaten buyers, moving our market closer to a sequence of independent, perfectly competitive markets. ${ }^{12}$

Both in monopoly and oligopoly pricing games, the presence of human buyers leads to lower prices as compared to simulated demand. This has been attributed to actual or threatened demand withholding by human buyers (see Holt, 1995 or Brown Kruse, 2008 and the references therein.) Countervailing buyer power may also become an issue with human buyers (see the overview by Ruffle 2009). These results provided suggestions for designing our treatments with automated and human buyers.

The economic effects of taxation in the context of markets is a core question in public finance. Who bears the burden of a unit sales tax? How does the allocation of this burden between buyers and sellers depend on the market conditions and the competition between sellers? Why is it easier for a Bertrand competitor to shift the burden of a tax than for a monopolist? What is the excess burden of a tax? And how does it depend on the prevailing market conditions? These questions are addressed in each and every textbook on taxation. Our analysis is - to the best of our knowledge - the first systematic experimental study that considers tax-burden shifting and the size of the excess burden of taxation as a function of market power.

\footnotetext{
${ }^{11}$ See also Ruffle (2000), Engle-Warnick and Ruffle (2005) and the survey by Ruffle (2009) on contervailing buyer power.

${ }^{12}$ Despite the wholly different research question in our paper, our results on Bert-Real also contribute to the research question in Tyran and Engelmann (2005). They find a substantial amount of boycott and we basically find no boycott. We find that both prices above marginal cost and boycott tend to disappear in a context without strategic supply withholding. Higher prices and the boycott behavior in their study may be driven by the assumption about sellers' withholding power.
} 


\section{$5 \quad$ Experimental results}

We report the results of the experiment in four steps. First, we give a quick overview of the results by providing and discussing a table with summary statistics. Second, we test Hypotheses 1 and 2 regarding the pass-through of the tax burden from sellers to buyers. Third, for the purpose of testing Hypotheses 3 and 4, we estimate the demand curve in the MonREAL treatment for "earlier" periods and check whether, with the help of this estimated demand, pricing behavior of monopolists can be predicted for "later" periods. Finally, we analyze the excess burden in the treatments with real buyers.

Overview of the results. We start with Table 2, which compares the equilibrium values for players who maximize their monetary payoffs with the average outcomes observed in the experiment. Columns 2-4 show results for the monopoly markets, while columns 5-7 show results for the Bertrand markets. For each of the two market forms, one column shows the values predicted by theory while the two columns to the right of it show the results for markets with simulated and real (human) demand. To purge the data of learning effects at the beginning of sessions, in Table 2 we report results of experienced behavior, i.e., from periods 6-10 of each phase of the experiment.

Let us first concentrate on prices. With respect to both Bertrand markets, we observe that the predictions of theory are quite accurately borne out by the data. That is, Bertrand competition pushes prices down to sellers' unit costs. Accordingly, an increase in unit costs increases prices by the cost increase, and this implies that the sellers can shift the entire tax burden on to the buyers, which seems to be true in both experimental Bertrand markets.

The outcome for monopoly markets with simulated demand is also largely in line with the theory prediction. Although firms in the first phase of the experiment price slightly lower than in the textbook equilibrium, the average observed price increases only slightly with the tax rate. However, the outcome in the monopoly case with real demand clearly differs from the textbook outcome. Indeed, prices are substantially lower than in the textbook equilibrium, buyer boycott exists, and the monopolist can increase the equilibrium price by about $37 \%$ of the tax-induced increase in production cost. To further illustrate the results in the monopoly treatments, let us compute the "monopoly effectiveness index": $M=\left(\pi^{a}-\pi^{c}\right) /\left(\pi^{m}-\pi^{c}\right)$, where $\pi^{a}$ is actual profit, $\pi^{c}$ is profit at the competitive equilibrium and $\pi^{m}$ is monopoly profit calculated as in the textbook (Holt 1995). ${ }^{13}$ For experienced behavior in the MonSim treatment, we find an average $M=0.89$

\footnotetext{
${ }^{13}$ For this index $M=1(M=0)$ means that the monopolist achieves monopoly (perfectly competitive) profits.
} 


\begin{tabular}{|c|c|c|c|c|c|c|}
\hline & \multicolumn{3}{|c|}{ Monopoly } & \multicolumn{3}{|c|}{ Bertrand } \\
\hline & Theory & MonSim & MonReaL & Theory & BERTSim & BERTREAL \\
\hline Market Price & 24 & 22.98 & 16.43 & 9 & 8.97 & 8.90 \\
\hline$[\operatorname{tax}=2]$ & & $(0.47)$ & $(0.50)$ & & $(0.06)$ & $(0.06)$ \\
\hline Market Price & 24 & 23.42 & 17.9 & 13 & 13 & 12.97 \\
\hline$[\operatorname{tax}=6]$ & & $(0.24)$ & $(0.40)$ & & $(0)$ & $(0.03)$ \\
\hline Difference & 0 & 0.44 & 1.47 & 4 & 4.03 & 4.07 \\
\hline No. units bought & 4 & 3.92 & 3.03 & 4 & 4 & 3.83 \\
\hline$[\operatorname{tax}=2]$ & & $(0.08)$ & $(0.20)$ & & $(0)$ & $(0.07)$ \\
\hline No. units bought & 4 & 4 & 3.23 & 4 & 4 & 3.8 \\
\hline$[\operatorname{tax}=6]$ & & (0) & $(0.18)$ & & $(0)$ & $(0.07)$ \\
\hline Difference & 0 & 0.08 & 0.2 & 0 & 0 & -0.03 \\
\hline Avg. total profits firms & 62 & 55.4 & 22.42 & 2 & 1.87 & 1.52 \\
\hline$[\operatorname{tax}=2]$ & & $(1.70)$ & $(1.69)$ & & $(0.23)$ & $(0.22)$ \\
\hline Avg. total profits firms & 46 & 43.68 & 16.68 & 2 & 2 & 1.77 \\
\hline$[\operatorname{tax}=6]$ & & $(0.94)$ & $(1.43)$ & & $(0)$ & $(0.14)$ \\
\hline Difference & -16 & -11.72 & -5.73 & 0 & 0.13 & .25 \\
\hline Avg. total profits buyers & 2 & & 26.12 & 62 & & 59.82 \\
\hline$[\operatorname{tax}=2]$ & & & $(2.60)$ & & & $(1.13)$ \\
\hline Avg. total profits buyers & 2 & & 22.12 & 46 & & 43.83 \\
\hline$[\operatorname{tax}=6]$ & & & $(2.02)$ & & & $(0.88)$ \\
\hline Difference & 0 & & -4.00 & -16 & & -15.98 \\
\hline Tax revenue & 8 & & 6.07 & 8 & & 7.67 \\
\hline$[\operatorname{tax}=2]$ & & & $(0.39)$ & & & $(0.14)$ \\
\hline Tax revenue & 24 & & 19.4 & 24 & & 22.80 \\
\hline$[\operatorname{tax}=6]$ & & & $(1.10)$ & & & $(0.45)$ \\
\hline Difference & 16 & & 13.33 & 16 & & 15.13 \\
\hline
\end{tabular}

Note: Standard errors in parentheses (based on market averages). Data from Periods 6-10 of each phase.

Table 2: Summary of experimental results 
(when $t=2$ ) and $M=0.95$ (when $t=6$ ). For experienced behavior in treatment MonReal, these numbers are $M=0.34$ (when $t=2$ ) and $M=0.33$ (when $t=6) .{ }^{14}$

In the treatments with real buyers, we can calculate the total burden for firms and buyers that results from the tax increase, and the impact on welfare (as in equations (3), (4), and (5)). With Bertrand competition, the firms' profits are almost unaffected by the tax increase whereas the buyers' profits decrease, as predicted by the theory. The decrease in profits, however, is offset by the higher tax revenue. In treatment MonREAL, both the profit of the monopolist and the profits of the buyers decrease when the tax is increased, but the total decrease in profits is smaller than the additional tax revenue, suggesting that the tax increase generates a welfare gain.

Price-setting in monopoly and Bertrand markets. To test Hypotheses 1 and 2 as well as additional hypotheses in a compact way, we first run a regression of the form $p_{i t}=$ $\alpha V A R S+\varepsilon_{i t}$, where $p_{i t}$ is the market price in market $i$ in period $t$ and $\varepsilon_{i t}$ is the overall error component. The vector $V A R S$ contains treatment dummies (MonSim, MonReal, BertSim, and BERTREAL) and interaction terms of the treatment dummies and the dummy HiGHTAX indicating the second phase of the experiment when the tax is increased to $t=6$. Since we suppress the constant in the regression equation, the coefficients of the treatment dummies indicate the average prices in the first phase of the experiment when the tax is low $(t=2)$, while the interaction terms between treatment dummies and the dummy HighTAX indicate the average price increase in the four treatments from the first phase (when the tax is low) to the second phase of the experiment (when the tax is high). ${ }^{15}$ To test the hypotheses, we then perform two-tailed Wald tests. ${ }^{16}$ The

\footnotetext{
${ }^{14}$ For the final period in the markets reported in Smith (1981), Holt (1995) finds the following numbers: doubleauction monopoly: $M=0.36$; posted-bid monopoly: $M=0.15$; posted-offer monopoly: $M=1.0$. Plott (1989) remarks that the likely reason for the failure of the monopolist in the double auction to exercise market power is the fact that buyers in this institution do not behave passively as price takers but engage in withholding purchases. This behavior causes the monopolist to price more cautiously. This explanation is in line with the observations in our monopoly treatments, where, with human buyers in the Mon-REAL treatment, we also observe demand withholding.

${ }^{15}$ To control for the possible non-independence of prices stemming from the same market, we estimated the regression equation using the cluster option provided by 'STATA' on individual markets. This option does not affect the estimated coefficients but estimates the standard errors using robust variance matrix calculations that relax the assumption of independence of errors within each market (cluster). For more details, see STATA Corp. (1999, vol. 3, pp. 156-158 and 178-179), White (1980), and Rogers (1993).

${ }^{16}$ Test results are the same when we perform $t$ tests on average prices of each individual market.
} 
results for experienced behavior (periods 6-10 and 16-20) are reported in Table $3 .{ }^{17}$

The results with respect to the Bertrand markets are most clear-cut. With simulated and real buyers alike, it cannot be rejected that the tax increase is fully shifted to the consumers: the coefficients of the interaction terms BertSim*HighTax and BERTREAL*HighTax are not significantly different from 4 (which is the amount by which the tax increases). Moreover, in the BERTSim treatment, the average price in the first phase of the experiment does not significantly differ from 9, as theoretically predicted. This is not the case for treatment BERTREAL. Note, however, that the average market price in the first phase of this treatment is virtually 9. Finally, a comparison of the estimated price increases from the first to the second phase of the experiment across the two Bertrand markets suggests no statistical difference (second-to-last line in Table 3). We conclude that the two Bertrand markets work very similarly and that hypotheses 1 and 2 on tax incidence in Bertrand markets are confirmed.

Let us now turn to the monopoly markets. In the MonSim treatment, the interaction term MonSim $*$ Hightax for the second phase (with $t=6$ ) is not significantly different from zero, supporting the hypothesis that monopolists in this treatment bear the full burden of an additional tax. The average market price in phase 1 of the MonSim treatment is 22.98 , and the test result on this coefficient indicates that the average price is not significantly different from 24 , as suggested by theory.

In the MonReal treatment, the average market price (16.43) in phase 1 is significantly smaller than 24, and the interaction term with the high-tax dummy for phase 2 is significantly different from zero. This means that, as already discussed earlier, monopolists in the MONREAL treatment are effectively constrained by the presence of real buyers compared to automated demand, but can pass on some of the higher costs due to the tax increase to buyers. Thus, Hypothesis 2 is confirmed. Finally, note that it cannot be rejected that the tax shifting is the same across the two monopoly treatments.

Result 1 With automated demand, there is full tax shifting in the Bertrand markets, but there is no significant tax shifting under monopoly.

Result 2 With real buyers, there is full tax shifting with Bertrand price competition and significant but incomplete tax shifting under monopoly.

\footnotetext{
${ }^{17}$ Using only dummies in the above regression equation, the coefficients of the treatment dummies and the interaction effects are equal to the average prices and the differences across phases of the experiment reported in the first lines of Table 2. Nevertheless, for convenience we report both the coefficients and the test results in Table 3.
} 


\begin{tabular}{|c|c|c|}
\hline \multicolumn{3}{|c|}{$\begin{aligned} p_{i t}= & \alpha_{1} \text { BertSim }+\alpha_{2} \text { BertReal }+\alpha_{3} \text { MonSim }+\alpha_{4} \text { MonReal }+\alpha_{5} \text { BertSim } * \text { HighTax } \\
& +\alpha_{6} \text { BertReaL } * \text { HighTaX }+\alpha_{7} \text { MonSim } * \text { HighTaX }+\alpha_{8} \text { MonReAL } * \text { HighTaX }+\varepsilon_{i t}\end{aligned}$} \\
\hline \multicolumn{3}{|l|}{ Estimation results } \\
\hline$\alpha_{1}(\mathrm{BERTSIM})$ & $8.97^{* * *}$ & $(0.078)$ \\
\hline$\alpha_{2}(\mathrm{BERTREAL})$ & $8.9^{* * *}$ & $(0.044)$ \\
\hline$\alpha_{3}($ MONSIM $)$ & $22.98^{* * *}$ & $(0.625)$ \\
\hline$\alpha_{4}(\mathrm{MonREAL})$ & $16.43^{* * *}$ & $(1.057)$ \\
\hline$\alpha_{5}($ BERTSim $*$ HighTAX $)$ & $4.03^{* * *}$ & $(0.078)$ \\
\hline$\alpha_{6}($ BERTREAL $*$ HighTAX $)$ & $4.07^{* * *}$ & $(0.065)$ \\
\hline$\alpha_{7}(\operatorname{MonSim} *$ HighTAX $)$ & 0.44 & $(0.693)$ \\
\hline$\alpha_{8}($ MonREAL $*$ HighTax $)$ & $1.47^{* *}$ & $(0.505)$ \\
\hline$R^{2}$ & \multicolumn{2}{|c|}{0.988} \\
\hline$N$ & \multicolumn{2}{|c|}{280} \\
\hline
\end{tabular}

Tests of Hypotheses 1 and 2

$H_{0}: \alpha_{5}=4$

$p=0.6801$

$H_{0}: \alpha_{7}=0$

$p=0.5413$

$H_{0}: \alpha_{6}=4$

$p=0.3316$

$H_{0}: \alpha_{8}=0$

$p=0.0175$

\section{Additional Tests}

$H_{0}: \alpha_{1}=9$

$p=0.6801$

$H_{0}: \alpha_{2}=9$

$p=0.0474$

$H_{0}: \alpha_{3}=24$

$p=0.1371$

$H_{0}: \alpha_{4}=24$

$p<0.0001$

$H_{0}: \alpha_{5}=\alpha_{6}$

$p=0.5914$

$H_{0}: \alpha_{7}=\alpha_{8}$

$p=0.2749$

Notes: ${ }^{* * *}$ significant at $1 \%$. Standard errors in parentheses. $H_{0}$ tested by means of two-tailed Wald tests.

Data from Periods 6-10 of each phase (experienced behavior).

Table 3: Test results for price effects 
Demand withholding and optimization in the monopoly case. We now turn to the outcomes that differ most noticeably from the textbook outcome: monopoly with real buyers. We test the theory according to which monopolists use early periods to find out about the buyers' demand function, $D(p)$, given the monopolist's selling price. For this purpose, we first estimate the buying behavior of the "average" buyer by means of a logit function of the form

$$
\operatorname{Pr}\left(\text { buy }_{i t}\right)=F\left(\beta_{0}+\beta_{1} p_{k t}+v_{i}+\varepsilon_{i t}\right)
$$

where buyit is the acceptance decision of subject $i$ in period $t$ (buyit equals 1 if subject $i$ bought a unit in period $t$, otherwise it equals 0 ), $p_{k t}$ is the price set by monopolist $k$ in period $t$, and $F$ is the logit function $F(x)=1 /(1+\exp (x))$. Recall that there are four real (human) buyers in each market in the MonReAL treatment. Hence, we assume that the demand function, $D(p)$, of a typical monopolist in the MonREAL treatment is simply given by $D(p)=4 F(p)=4\left(1 /\left(1+\exp \left(\widehat{\beta}_{0}+\widehat{\beta}_{1} p\right)\right)\right)$, where $\widehat{\beta}_{0}$ and $\widehat{\beta}_{1}$ are the estimated parameters in equation (6). Note that estimating equation (6) models purchasing behavior of the average buyer. We refrain from estimating buyer behavior for each subject (and aggregating demand per market) for lack of a sufficient number of observations at the individual level.

Having estimated the average demand function in the MONREAL treatment using the observations in periods $1,2, \ldots, T-1$ by means of equation (6), we then predict the average price chosen by monopolists in the MonReAL treatment in period $T$ as

$$
\arg \max _{p}\{D(p)(p-c-t)\}
$$

where $c=6.5$ is the unit production cost and $t \in\{2,6\}$ is the tax. Moreover, we predict the excess burden of the tax based on the estimated demand function using the predicted price for period $T$. The results are shown in Table 4.

Table 4 should be read row by row. The entry in the first column indicates the period for which we want to predict the average price chosen by monopolists (i.e., period $T=10$ in row 2). The entry in the second column indicates the periods we use to estimate the demand functions monopolists faced in the past (i.e., periods $1,2, \ldots, 9$ in row 2 ). The entries in the third and fourth column show the estimates of the parameters in the demand function (i.e., $\beta_{0}=14.98$ and $\beta_{1}=-0.83$ in row 2). Finally, the entries in column 5 and 6 report, respectively, the predicted and the average observed price in period $T$ (i.e., 16.06 and 16.33 in row 2), and column 7 states the loss of surplus, or excess burden, due to demand withholding, $(1-F(p)) m(24.5-c)$, predicted 


\begin{tabular}{|c|c|c|c|c|c|c|}
\hline & $\begin{array}{c}\text { Time interval } \\
\text { used for estimation }\end{array}$ & $\beta_{0}$ & $\beta_{1}$ & $\begin{array}{l}\text { Predicted } p \\
\text { in period } T\end{array}$ & $\begin{array}{l}\text { Observed } p \\
\text { in period } T\end{array}$ & $\begin{array}{c}\text { Excess burden } \\
\text { in period } T\end{array}$ \\
\hline$T=10$ & $1,2, \ldots, T-1$ & $\begin{array}{c}14.98^{* * *} \\
(2.90)\end{array}$ & $\begin{array}{c}-0.83^{* * *} \\
(0.17)\end{array}$ & 16.06 & 16.33 & 11.50 \\
\hline$T=20$ & $11,12, \ldots, T-1$ & $\begin{array}{c}34.26^{* * *} \\
(8.13)\end{array}$ & $\begin{array}{c}-1.77^{* * *} \\
(0.43)\end{array}$ & 17.84 & 17.83 & 7.21 \\
\hline$T=9$ & $1,2, \ldots, T-1$ & $\begin{array}{c}14.06^{* * *} \\
(2.92)\end{array}$ & $\begin{array}{c}-0.78^{* * *} \\
(0.17)\end{array}$ & 16.06 & 16.17 & 12.26 \\
\hline$T=19$ & $11,12, \ldots, T-1$ & $\begin{array}{c}39.86^{* * *} \\
(9.69)\end{array}$ & $\begin{array}{c}-2.06^{* * *} \\
(0.51)\end{array}$ & 18.17 & 17.91 & 6.16 \\
\hline$T=11$ & $1,2, \ldots, T-1$ & $\begin{array}{c}12.34^{* * *} \\
(2.37)\end{array}$ & $\begin{array}{c}-0.67^{* * *} \\
(0.14)\end{array}$ & 16.32 & 18.00 & \\
\hline
\end{tabular}

Note: ${ }^{* * *}$ significant at $1 \%$. Standard errors in parentheses.

Table 4: Prediction of the monopoly price in period $T$ based on observed buyer behavior in early periods (MONREAL treatment)

on the basis of the estimated demand. In column 7, the difference between the entries in row 2 and row 3 (and row 4 and 5, respectively) describes the change in the excess burden, which corresponds to the welfare effect of the tax increase (see equation (3)).

The sign of the slope of the estimated demand function is given by the sign of the coefficient $\beta_{1}$. All estimates of $\beta_{1}$ reported in Table 4 are negative and highly significantly different from 0 . We conclude that all demand functions reported in Table 4 are downward-sloping and are thus different from block demand (Hypothesis 3).

Result 3 With real buyers, the demand curve is downward-sloping.

Next, consider row 2 (row 3), which shows the results concerning the prediction of the average price chosen in period 10 (period 20) using the information on buyer behavior in periods 1 to 9 (11 to 19 ). We find that the estimated average prices are very much on target, confirming Hypothesis 4. In fact, the predicted price for period 10 is 16.06 , while we observe an average price of 16.33 in this period. Moreover, the predicted price for period 20 is 17.84 , while the observed average price in this period is 17.83. Rows 4 and 5 in Table 4 show the predictions for periods 9 and 19 (using information on buyer behavior in periods 1 to 8 and 11 to 18, respectively). Again, 
the predictions are quite accurate. Perhaps not surprisingly, using the information of periods 1 to 10 (where the tax is equal to 2) to predict the average price chosen in period 11 (where the tax is increased to 6) clearly fails, as the average observed price is about 1.7 units higher than the estimated price in period 11. Predicting the expected loss of surplus which is caused by demand withholding suggests that the excess burden decreases when the tax is increased. Thus, by weakening demand withholding, the tax increase causes a welfare gain.

Finally, although there is also some demand withholding in the BERTREAL treatment (see Table 2), estimations show that the demand function, e.g. for periods 1 to 9 , is not downwardsloping. Summarizing, we can confirm Hypothesis 4:

Result 4 With real buyers, in later periods it appears that the monopolist chooses the price that maximizes his payoff, based on observed buying decisions in earlier periods.

Efficiency and excess burden. An increase in the tax may actually decrease, increase or hold constant the expected loss of surplus. To illustrate the effects consider Figure 1. The solid line $A B$ is meant to describe the relationship between $p$ and $F(p)$ for $t=2$, which is the expected demand per buyer as a function of $p$. By way of illustration, let this go up linearly from $F(p=25)=0$ to $F(p=9)=1$. In this case the monopolist chooses the price at which marginal cost equals marginal revenue, which is true at $F(p)=1 / 2$ and leads to a monopoly price of 17 and an expected loss of surplus equal to the rectangle CDEF. Now consider $t=6$, and assume that the stochastic demand remains linear, but passes through $F(25)=0$ and $F(13)=1$, as line $A B^{\prime}$. This rotation around point $A$ can be interpreted as a similar boycott behavior, whereby no customer is willing to pay above his monetary reservation prize, but all customers are willing to buy if the monopolist charges only the smallest feasible price that exceeds the tax-inclusive production cost. In this case the monopoly quantity stays at $F(p)=1 / 2$, inducing exactly the same excess burden as for $t=2$. As suggested by this example, an increase and a decrease in the excess burden are both feasible if the change in the demand function is slightly different.

In the following we test for the effect of the tax increase on the monetary payoffs of firms and buyers and on the excess burden of the tax increase for the treatments with real (human) buyers. For this purpose, we estimate equation $y_{i t}=\alpha V A R S+\varepsilon_{i t}$, where $y_{i t}$ refers to one of these three measures of the tax burden (payoff loss to firms, payoff loss to buyers, and excess burden) and the vector $V A R S$ contains dummies for the BERTREAL and MONREAL treatments and interaction terms with phase 2 (where $t=6$ ). Hence, as in the price regressions reported above, the interaction 


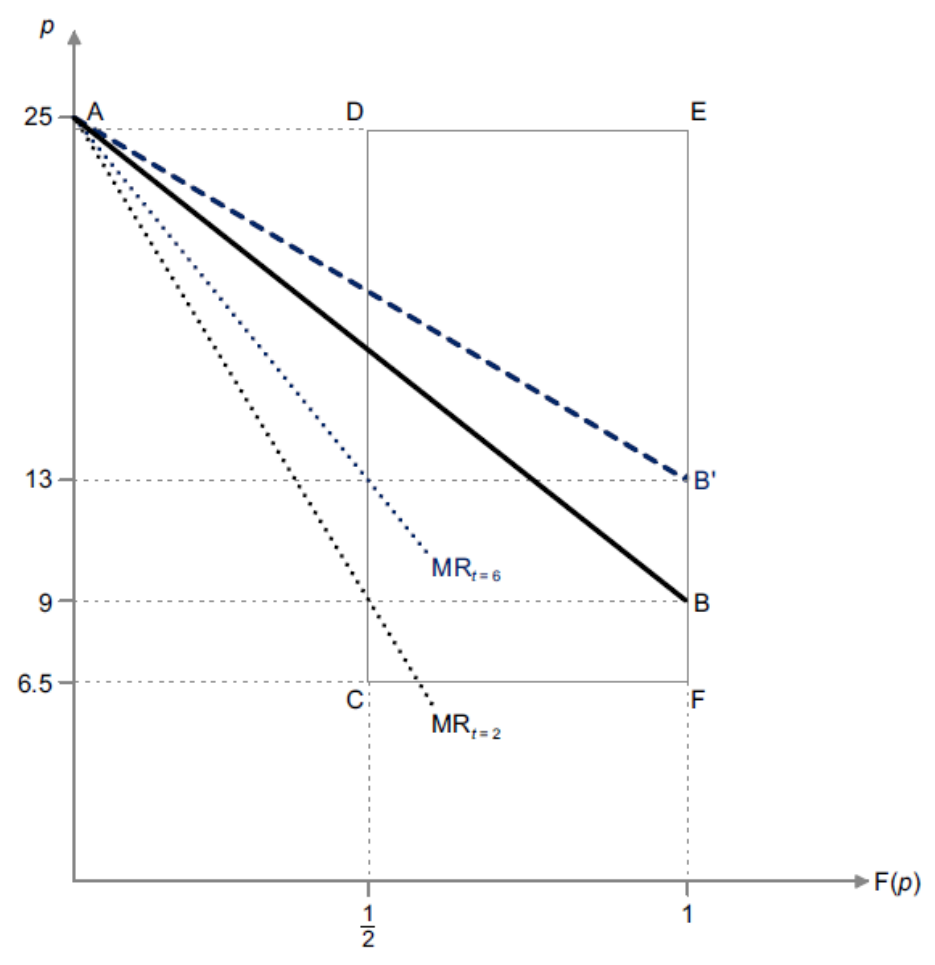

Figure 1: Monopoly pricing with strategic boycott uncertainty: the effect of a tax increase

terms measure the effect of the tax increase from phase 1 to phase 2 of the experiment. ${ }^{18}$ The results are shown in Table 5. The estimation confirms that in the Bertrand markets, the firms' profits are not significantly affected by the tax increase, whereas the buyers' payoffs significantly decrease (see the significance levels on the BERTREAL*HIGHTAX variable). In the monopoly treatment, both the firm's and the buyers' payoffs decrease when the tax is increased, but only the effect on firms' profits is significant.

With Bertrand competition, the excess burden is only borderline significantly different from zero $(p=0.096)$, and it is not affected by the tax increase. There is only weak demand withholding, as the average number of units bought (about 3.8) is close to the maximum demand of 4 units. In the monopoly case with real buyers, however, the excess burden is significantly larger than zero, confirming Hypothesis 5. Moreover, it follows from the significance level of the MonREAL*HighTAX interaction term that the excess burden does not significantly change when the tax is increased. The sign of the coefficient (-3.60) may suggest that, although there can be countervailing effects of

\footnotetext{
${ }^{18}$ As in the price-effect regressions, we control for possible non-independence of observations that stem from the same market.
} 


\begin{tabular}{|c|c|c|c|c|c|c|}
\hline \multicolumn{7}{|c|}{ Estimated equation: } \\
\hline \multicolumn{7}{|c|}{$y_{i t}=\alpha_{1}$ BertReaL $+\alpha_{2}$ BertReaL $*$ HighTax $+\alpha_{3}$ MonReAL $+\alpha_{4}$ MonReaL $*$ HighTaX $+\varepsilon_{i t}$} \\
\hline \multirow{2}{*}{$\begin{array}{l}\text { Estimation results } \\
\alpha_{1}(\mathrm{BERTREAL})\end{array}$} & \multicolumn{2}{|c|}{ Profit of firms } & \multicolumn{2}{|c|}{ Profit of buyers } & \multicolumn{2}{|c|}{ Excess burden } \\
\hline & $1.52^{* * *}$ & $(0.144)$ & $59.82^{* * *}$ & $(1.430)$ & $3.00^{*}$ & $(1.464)$ \\
\hline$\alpha_{2}($ BertReAL $*$ HighTax $)$ & 0.25 & $(0.255)$ & $-15.98^{* * *}$ & $(0.998)$ & 0.60 & $(1.121)$ \\
\hline$\alpha_{3}($ MonREAL $)$ & $22.42^{* * *}$ & $(2.280)$ & $26.12^{* * *}$ & $(4.732)$ & $17.40^{* * *}$ & $(3.448)$ \\
\hline$\alpha_{4}($ MonReal $*$ HighTax $)$ & $-5.73^{* *}$ & $(1.871)$ & -4.00 & $(2.852)$ & -3.60 & $(4.104)$ \\
\hline$R^{2}$ & \multicolumn{2}{|c|}{0.845} & \multicolumn{2}{|c|}{0.947} & \multicolumn{2}{|c|}{0.401} \\
\hline$N$ & \multicolumn{2}{|c|}{120} & \multicolumn{2}{|c|}{120} & \multicolumn{2}{|c|}{120} \\
\hline
\end{tabular}

Note: ${ }^{* * *}$ significant at $1 \%,{ }^{* *}$ significant at $5 \%,{ }^{*}$ significant at $10 \%$. Standard errors in parentheses.

Data from Periods 6-10 of each phase.

Table 5: Results of profit and excess-burden regressions

an increase of the tax, in our case the positive effects on welfare prevail. To summarize, Hypothesis 5 on the excess burden in the regime with real buyers is confirmed by the results shown in Table 5 .

Result 5 The Bertrand markets with real buyers are (weakly) efficient. In the case of monopoly with real buyers, there is a significantly positive excess burden.

\section{Conclusion}

The experimental analysis in this paper tested the most salient predictions of public finance theory about the role of market power for tax incidence.

- We find that the tax incidence effects in Bertrand markets are an almost perfect mapping of results in public finance theory: a tax increase is fully shifted to the consumers via higher prices, where the equilibrium price stays very close to (tax-inclusive) marginal cost. This holds regardless of whether the buyers' decisions are simulated and deterministic, or whether buyers are real (human) players. Demand withholding or boycott does not play an important role. Hence, there was no excess burden in the Bertrand markets we analyzed.

- The experimental results in the case of monopoly with simulated buyers are also fully in line with tax incidence results for standard monopoly theory. The monopolist bears a major share in the cost of an increased tax. 
- The presence of real buyers has a significant and positive impact on prices that could be predicted from the theory of buyer boycott. Buyers who are real (human) players may refuse to buy at prices that they consider too high, even if the prices are lower than their monetary reservation prices. The observed monopoly prices are significantly below the price predicted for monopoly in the textbook. Also, the monopolist significantly increases the market price as a reaction to the tax increase. Both the monopolist and the buyers share in the tax burden. The monopoly prices can be seen as profit-maximizing monopoly price choices by a monopolist who takes the buyers' possible boycott behavior into consideration and uses earlier purchase decisions for the formation of a belief about buyer decisions. In the case of monopoly with real buyers, demand withholding leads to a welfare loss.

- We identify several theoretical reasons for why an increase in the tax may, but need not, increase the welfare loss in the monopoly market that is caused by possible boycott behavior. A tax increase can reduce the welfare loss from monopoly in such a framework. In the experimental market we find that the tax increase reduced the welfare loss and had a negative marginal excess burden.

The experimental analysis of the role of market power for the incidence of a tax was motivated by a sharp contrast between public perceptions and the predictions of public economic theory. In the public debate it is frequently argued that market power enables firms to maintain their profit margin in times of cost increases by passing a cost increase on to the consumers. In a similar vein, these public perceptions are expressed well by the participants in our experiment. At the end of the experiment, we asked the participants (among other questions) whether they (rather or fully) agreed to or (rather or fully) disagreed with the following statement:

A monopolist is much more able to pass an increase in the VAT on to the consumers than a firm that is competing with many other firms.

Independent of the treatment, more than 50 percent of the participants fully agreed to this statement, and an additional 30 percent rather agreed. These numbers may be considered as surprisingly strong evidence for these perceptions (particularly given that these persons had just minutes before participated in one of the experimental sessions that produced the opposite results).

These public perceptions contrast strongly with textbook public finance theory. While providing a wealth of results for less clear-cut market conditions, textbook public finance makes 
precisely inverse predictions. It suggests that Bertrand competitors can completely shift the tax burden, whereas a monopolist cannot; it also offers a strong intuition for this result. Most of our experimental results contradict the widely held perceptions and are fully in line with the textbook intuition in public finance. This is true in particular if firms could firmly rely on (automated) demand choices determined purely by buyers' monetary rewards. If (human) buyers make purchase decisions, this causes strategic uncertainty. This effect could not affect the incidence results for Bertrand markets, but it changes the tax incidence of monopoly markets and brings the incidence outcomes closer to public perceptions; it places the monopolist firm in a position in which it may shift part of the tax on to buyers.

\section{References}

[1] Besley Timothy J., and Harvey S. Rosen, 1999. Sales taxes and prices: An empirical analysis. National Tax Journal 52(2), 157-178.

[2] Bishop, Robert L., 1968, The effects of specific and ad valorem taxes. Quarterly Journal of Economics, 82(2), 198-218.

[3] Bloomfield, Robert, Maureen O'Hara, and Gideon Saar, 2009. How noise trading affects markets: an experimental analysis. Review of Financial Studies 22(6), 2275-2302.

[4] Borck, Rainald, Dirk Engelmann, Wieland Müller, and Hans-Theo Normann, 2002. Tax liability-side equivalence in experimental posted-offer markets. Southern Economic Journal 68(3), 672-682.

[5] Brown Kruse, J. 2008. Simulated and Real Buyers in Posted Offer Markets. In: Handbook of Experimental Results, Vol. 1, Vernon L. Smith and Charles Plott, eds, North Holland/Elsevier Press, Amsterdam, 71-76.

[6] Chouinard, Hayley, and Jeffrey M. Perloff, 2004. Incidence of federal and state gasoline taxes. Economics Letters 83(1), 55-60.

[7] Devereux, Michael P., and Gauthier Lanot, 2003. Measuring tax incidence: an application to mortgage provision in the UK. Journal of Public Economics 87(7-8), 1747-1778.

[8] Dufwenberg, Martin, and Uri Gneezy, 2000. Price competition and market concentration: an experimental study. International Journal of Industrial Organization,18(1), 7-22. 
[9] Dufwenberg, Martin, and Uri Gneezy, 2002. Information disclosure in auctions: an experiment. Journal of Economic Behavior \& Organization 48(4), 431-444.

[10] Engle-Warnick, Jim and Bradley J. Ruffle, 2005. Buyer Concentration as a Source of Countervailing Power: Evidence from Experimental Posted-Offer Markets. Available at SSRN: http://ssrn.com/abstract=310339.

[11] Fischbacher, Urs, 2007. z-Tree: Zurich Toolbox for Ready-made Economic Experiments. Experimental Economics 10(2), 171-178.

[12] Fouraker, Lawrence E. and Sidney Siegel. 1963. Bargaining Behavior. New York: McGraw-Hill.

[13] Fullerton, Don, and Gilbert E. Metcalf, 2002, Tax incidence. in: A.J. Auerbach and M. Feldstein, Handbook of Public Economics, Volume 4, Elsevier, Amsterdam

[14] Greiner, Ben, 2004. An Online Recruitment System for Economic Experiments. In: Kurt Kremer, Volker Macho (Eds.): Forschung und wissenschaftliches Rechnen 2003. GWDG Bericht 63, Göttingen: Ges. für Wiss. Datenverarbeitung, 79-93.

[15] Güth, Werner 1995. On ultimatum bargaining - A personal review. Journal of Economic Behavior and Organization 27:329-344.

[16] Hamilton Stephen F., 2009. Excise taxes with multiproduct transactions. American Economic Review 99(1), 458-471.

[17] Hehenkamp, Burkhard, and Wolfgang Leininger, 1999. A note on evolutionary stability of Bertrand equilibrium. Journal of Evolutionary Economics 9, 367-371.

[18] Holt, Charles A., 1995. Industrial Organization: A Survey of Laboratory Research. In: John H. Kagel and Alvin E. Roth (Eds.), Handbook of Experimental Economics, Princeton: Princeton University Press, 349-443.

[19] Kachelmeier, Steven J., Stephen T. Limberg, and Michael S. Schadewald, 1994. Experimental Evidence of Market Reactions to New Consumption Taxes. Contemporary Accounting Research 10, 505-45.

[20] Kenkel, Donald S., 2005. Are alcohol tax hikes fully passed through to prices? Evidence from Alaska. American Economic Review, Papers and Proceedings, 95(2), 273-277.

[21] Kerschbamer, Rudolf and Georg Kirchsteiger, 2000. Theoretically robust but empirically invalid? An experimental investigation into tax equivalence. Economic Theory 16, 719-34. 
[22] Kim, Donghun, and Ronald W. Cotterill, 2008. Cost pass-through in differentiated product markets: The case of US processed cheese, Journal of Industrial Economics, 56(1), 32-48.

[23] Levy-Garboua, Louis, David Masclet, and Claude Montmarquette, 2009. A behavioral Laffer curve: Emergence of a social norm of fairness in a real effort experiment. Journal of Economic Psychology 30(2), 147-161.

[24] Myerson, Roger B., and Mark A. Satterthwaite, 1983. Efficient Mechanisms for Bilateral Trading. Journal of Economic Theory 29(2), 265-281.

[25] Myles, Gareth D., 1995. Public Economics. Cambridge: Cambridge University Press.

[26] Nelson, Nick, 2008, How can investors offset inflation risks? UBS Investment Research, European Equity Strategy, July 9, 2008 (www.ubs.com/investmentresearch).

[27] Ortona, Guido, Stefania Ottone, Ferruccio Ponzano, and Francesco Scacciati, 2008. Labour supply in presence of taxation financing public services. An experimental approach. Journal of Economic Psychology 29(5), 619-631.

[28] Plott, Charles R., 1989. An updated review of industrial organization: applications of experimental methods. In: Richard Schmalensee and Robert D. Willig, Handbook of Industrial Organization, Volume II, Amsterdam: North-Holland, 1109-1176.

[29] Poterba James M., 1996. Retail price reactions to changes in state and local sales taxes. National Tax Journal 49(2), 165-176.

[30] Quirmbach, Herman C., Charles W. Swenson, and Cynthia C.Vines, 1996. An experimental examination of general equilibrium tax incidence. Journal of Public Economics 61(3), 337358.

[31] Riedl, Arno, and Jean-Robert Tyran, 2005. Tax liability side equivalence in gift-exchange labor markets. Journal of Public Economics 89(11-12), 2369-2382.

[32] Rogers, W. H., 1993. Regression standard errors in clustered samples. Stata Technical Bulletin $13,19-23$.

[33] Roth, Alvin E. 1995. Bargaining Experiments. In: The Handbook of Experimental Economics, ed. J.H. Kagel and A.E. Roth. Princeton: Princeton University Press, 253-331.

[34] Ruffle, Bradley J., 2000. Some Factors Affecting Demand Withholding in Posted-Offer Markets. Economic Theory 16(3), 529-544. 
[35] Ruffle, Bradley J., 2005. Tax and subsidy incidence equivalence theories: experimental evidence from competitive markets. Journal of Public Economics 89(8), 1519-1542.

[36] Ruffle, Bradley J., 2009. Buyer Countervailing Power: A Survey of the Theory and Experimental Evidence, In: Experiments and Antitrust Policy, J. Hinloopen and H.-T. Normann (eds.), Cambridge, U.K.: Cambridge University Press, 160-182.

[37] Seade, Jesus, 1985. Profitable Cost Increases and the Shifting of Taxation: Equilibrium Response of Markets in Oligopoly. Warwick Economic Research Papers No 260, University of Warwick.

[38] Sillamaa Mary-Anne, 1999. How work effort responds to wage taxation: An experimental test of a zero top marginal tax rate. Journal of Public Economics 73(1), 125-134.

[39] Smith, Vernon L., 1981. An Empirical Study of Decentralized Institutions of Monopoly Restraint. In: James P. Quirk and George Horwich (Eds.): Essays in Contemporary Fields of Economics in Honor of E.T. Weiler (1914-1979), West Lafayette: Purdue University Press, 83-106.

[40] STATA Corp. 1999. Reference manual, release 6, STATA Press Texas.

[41] Stern, Nicolas, 1987. The effects of taxation, price control and government contracts in oligopoly and monopolistic competition. Journal of Public Economics 32(2), 133-158.

[42] Sutter, Matthias, and Hannelore Weck-Hannemann, 2003. Taxation and the veil of ignorance - A real effort experiment on the Laffer curve. Public Choice 115(1-2), 217-240.

[43] Tyran, Jean-Robert and Dirk Engelmann, 2005. To Buy or Not to Buy? An Experimental Study of Consumer Boycotts in Retail Markets. Economica 72, 1-16.

[44] White, H., 1980. A heteroskedasticity-consistent covariance matrix estimator and a direst test for heteroskedasticity. Econometrica 48, 817-30.

[45] Young, Douglas J. and Agnieszka Bielinska-Kwapisz, 2002. Alcohol taxes and beverage prices. National Tax Journal 55, 57-73. 


\section{Instructions for the MonReal treatment}

\section{Welcome to this experiment!}

\section{General Information}

- Please read these instructions carefully and completely.

- Please do not talk to your neighbors and keep quiet during the entire experiment.

- Raise your hand if you have a question. One of us will come to you.

- All participants in the experiment have been given the same instructions.

\section{Introduction}

- In this experiment you will repeatedly make decisions. By doing so you can earn money.

- Your gains are measured in Talers. How much you earn depends on your decisions and the decision of other participants.

- At the beginning of the experiment, each participant will receive an initial endowment of 25 Talers.

- At the end of the experiment your total sum of Talers will be determined by the sum of the initial endowment plus the number of Talers you earned in each round.

- At the end of the experiment you will receive 1 euro in cash for every 25 Talers. In addition, each participant will receive a participation fee of 4 euros.

- During the entire experiment, anonymity among participants and instructors will be kept.

- The experiment consists of two parts, each of which consists of 10 rounds. The rules for the first part will be explained now. The rules for the second part will be given after completion of the first part of the experiment.

\section{Description of the experiment}

- In this experiment you will act in a market in which there are sellers on one side and buyers on the other side of the market. In the following we will describe both sides of the market.

\section{Sellers}

- Sellers represent firms that manufacture and sell a product in this market.

- Each seller may sell up to four units of the product on the market. The production cost per unit sold is 6.50 Talers. In addition, each seller has to pay a tax of 2 Talers for each unit sold.

- In every round, each seller chooses the price at which he/she wishes to sell the product. This price must be a non-negative integer $(0,1,2,3 \ldots)$. By opting for this price, the seller declares that he/she wishes to sell up to four units of the product at this price.

- The seller's profit per round is calculated by the difference between the sales revenue and the cost: 
Seller's profit $=$ sales revenue - cost

- The sales revenue is equal to the chosen price multiplied by the number of units sold:

Sales revenue $=$ price $\times$ number of units sold

- The costs incurred are equal to the sum of production costs and tax per unit sold multiplied by the number of units sold:

$$
\begin{aligned}
\text { Cost } & =(\text { cost of production per unit }+ \text { tax per unit }) \times \text { number of units sold } \\
& =(6.50+2) \times \text { number of units sold } \\
& =8.50 \times \text { number of units sold }
\end{aligned}
$$

- So:

$$
\begin{aligned}
& \text { Seller's profit } \\
& \quad=(\text { sales revenue })-(\text { cost }) \\
& =(\text { price } \times \text { number of units sold })-(8.50 \times \text { number of units sold }) \\
& =(\text { price }-8.50) \times \text { number of units sold }
\end{aligned}
$$

- Please note that a seller will make a loss if he sells the units at a price lower than the total sum of the costs and tax per unit (i.e., 8.50 Talers).

- There will be exactly one seller in each market. At the beginning of the experiment, one participant will be randomly assigned to a market as the seller and will remain as seller in this market in all rounds of the two parts of the experiment.

- At the beginning of each round, the seller of a market will choose a selling price. The price will be presented to the buyers, who then have to decide whether or not to buy at this price. The seller can sell the units (up to four) on the market.

\section{Buyers}

- Each buyer can buy exactly one unit on the market. The value of a unit bought is 24.50 Talers for each buyer. (The value is determined by the fact that the laboratory pays exactly this price to the buyers for each unit bought.)

- If a buyer purchases one unit of the product, the buyer's profit per round is the difference between the unit value and the purchase price:

$$
\text { Buyer's profit }=\text { value }- \text { price }=24.50 \text { - price }
$$

- There will be four buyers in each market. This means, the maximum demand in a market is four units.

- At the beginning of the experiment, four participants will be randomly assigned as buyers and will then remain as buyers in this market in all rounds of the two parts of the experiment.

- Once the seller has chosen a selling price at the beginning of a round, this price will be presented to the buyers. The buyers then have to decide whether or not to buy at this price. 
- If a buyer does not want to buy a unit at that price, he or she may press the push-button specifying "Do not Buy".

- If a buyer wants to buy a unit at that price, he or she can press the push-button indicating "Buy at this price".

- Please note that a buyer will make a loss if he/she buys a unit at a price that is higher than the value of a unit (i.e. higher than 24.50 Talers).

\section{Sequence of actions in the experiment}

- Each market consists of one seller (who can sell up to four units of the product) and four buyers (who can each purchase one unit). At the beginning of the experiment participants will be informed as to whether they are a seller or a buyer. The first phase of the experiment consists of 10 rounds. The sequence of a round in the first phase is as follows:

- At the beginning of each round, the seller of a market chooses a price at which he/she is obligated, depending on the demand, to sell four units. For this purpose, the seller chooses a non-negative integer $(0,1,2,3 \ldots)$ as a price, and confirms this by pressing the "OK" button.

- The price chosen by the seller will then be displayed to the buyers. Each buyer then has to independently decide whether or not to buy a unit of the product at the given price.

- To summarize the information in each round, the computer will then reveal the following information:

- Seller: own chosen price, the number of own units sold and own profit.

- Buyer: Lowest price chosen and the own profit. 


\section{Instructions for the MonSim treatment}

\section{Welcome to this experiment!}

\section{General Information}

- Please read these instructions carefully and completely.

- Please do not talk to your neighbors and keep quiet during the entire experiment.

- Raise your hand if you have a question. One of us will come to you.

- All participants in the experiment have been given the same instructions.

\section{Introduction}

- In this experiment you will repeatedly make decisions. By doing so you can earn money.

- Your gains are measured in Talers. How much you earn depends on your decisions.

- At the beginning of the experiment, each participant will receive an initial endowment of 25 Talers.

- At the end of the experiment your total sum of Talers will be determined by the sum of the initial endowment and the number of Talers you have earned in each round.

- At the end of the experiment you will receive 1 euro in cash for every 200 Talers. In addition, each participant will receive a participation fee of 4 euros.

- During the entire experiment, anonymity among participants and instructors will be kept.

- The experiment consists of two parts, each of which consists of 10 rounds. The rules for the first part will be explained now. The rules for the second part will be given after completion of the first part of the experiment.

\section{Description of the experiment}

- In this experiment you will act in a market in which there are sellers on one side and buyers on the other side of the market. In the following we will describe both sides of the market.

\section{Sellers}

- Sellers represent firms that manufacture and sell a product in this market.

- Each seller may sell up to four units of the product on the market. The production cost per unit sold is 6.50 Talers. In addition, each seller has to pay a tax of 2 Talers for each unit sold.

- In every round, each seller chooses the price at which he/she wishes to sell the product. This price must be a non-negative integer $(0,1,2,3 \ldots)$. By opting for this price, the seller declares that he/she wishes to sell up to four units of the product at this price.

- The seller's profit per round is calculated by the difference between the sales revenue and the cost: 
Seller's profit $=$ sales revenue - cost

- The sales revenue is equal to the chosen price multiplied by the number of units sold:

Sales revenue $=$ price $\times$ number of units sold

- The costs incurred are equal to the sum of production costs and tax per unit sold multiplied by the number of units sold:

$$
\begin{aligned}
\text { Cost } & =(\text { cost of production per unit }+ \text { tax per unit }) \times \text { number of units sold } \\
& =(6.50+2) \times \text { number of units sold } \\
& =8.50 \times \text { number of units sold }
\end{aligned}
$$

- So:

$$
\begin{aligned}
& \text { Seller's profit } \\
& \quad=(\text { sales revenue })-(\text { cost }) \\
& =(\text { price } \times \text { number of units sold })-(8.50 \times \text { number of units sold }) \\
& =(\text { price }-8.50) \times \text { number of units sold }
\end{aligned}
$$

- Please note that a seller will make a loss if he/she sells the units at a price lower than the total sum of the costs and tax per unit (i.e., 8.50 Talers).

- There will be exactly one seller in each market. At the beginning of the experiment, one participant will be randomly assigned to a market as the seller and will remain as seller in this market in all rounds of the two parts of the experiment.

- At the beginning of each round, the seller of a market will choose a selling price. The price will be presented to the buyers, who then have to decide whether or not to buy at this price. The seller can sell the units (up to four) on the market.

\section{Buyers}

- Each buyer can buy exactly one unit on the market. The value of a unit bought is 24.50 Talers for each buyer. (The value is determined by the fact that the laboratory pays exactly this price to the buyers for each unit bought.)

- If a buyer purchases one unit of the product, the buyer's profit per round is the difference between the unit value and the purchase price:

$$
\text { Buyer's profit }=\text { value }- \text { price }=24.50 \text { - price }
$$

- There will be four buyers in each market. This means, the maximum demand in a market is four units.

- There are no real buyers in this experiment. Instead, the buyers in all rounds of the two parts of the experiment are simulated by the computer. There are four computer-simulated buyers.

- Once the seller has chosen a selling price at the beginning of a round, this price will be presented to the simulated buyers. The simulated buyers then have to decide whether or not to buy at this price. 
- None of the simulated buyers will purchase a unit of the product if the price is higher than the 24.50 value of a unit.

- Each of the four simulated buyers will purchase one unit of the product at a price that is less than or equal to the 24.50 value of a unit.

\section{Sequence of actions in the experiment}

- Each market consists of one seller (who can sell up to four units of the product) and four simulated buyers (who can each purchase one unit). The first phase of the experiment consists of 10 rounds. The sequence of a round in the first phase is as follows:

- At the beginning of each round, the seller of a market chooses a price at which he/she is obligated, depending on the demand, to sell four units. For this purpose, the seller chooses a non-negative integer $(0,1,2,3 \ldots)$ as a price, and confirms this by pressing the "OK" button.

- The price chosen by the seller will then be displayed to the buyers. Each buyer then has to independently decide whether or not to buy a unit of the product at the given price.

- To summarize the information in each round, the computer will then reveal the following information:

- Chosen price, the number of units sold, and own profit. 


\section{Instructions for the BertReal treatment}

\section{Welcome to this experiment!}

\section{General Information}

- Please read these instructions carefully and completely.

- Please do not talk to your neighbors and keep quiet during the entire experiment.

- Raise your hand if you have a question. One of us will come to you.

- All participants in the experiment have been given the same instructions.

\section{Introduction}

- In this experiment you will repeatedly make decisions. By doing so you can earn money.

- Your gains are measured in Talers. How much you earn depends on your decisions and the decision of other participants.

- At the beginning of the experiment, each participant will receive an initial endowment of 25 Talers.

- At the end of the experiment your total sum of Talers will be determined by the sum of the initial endowment plus the number of Talers you have earned in each round.

- At the end of the experiment you will receive 1 euro in cash for every 25 Talers. In addition, each participant will receive a participation fee of 4 euros.

- During the entire experiment, anonymity among participants and instructors will be kept.

- The experiment consists of two parts, each of which consists of 10 rounds. The rules for the first part will be explained now. The rules for the second part will be given after completion of the first part of the experiment.

\section{Description of the experiment}

- In this experiment you will act in a market in which there are sellers on one side and buyers on the other side of the market. In the following we will describe both sides of the market.

\section{Sellers}

- Sellers represent firms that manufacture and sell a product in this market.

- Each seller may sell up to four units of the product on the market. The production cost per unit sold is 6.50 Talers. In addition, each seller has to pay a tax of 2 Talers for each unit sold.

- In every round, each seller chooses the price at which he/she wishes to sell the product. This price must be a non-negative integer $(0,1,2,3 \ldots)$. By opting for this price, the seller declares that he/she wishes to sell up to four units of the product at this price.

- The seller's profit per round is calculated by the difference between the sales revenue and the cost: 
Seller's profit $=$ sales revenue - cost

- The sales revenue is equal to the chosen price multiplied by the number of units sold:

Sales revenue $=$ price $\times$ number of units sold

- The costs incurred are equal to the sum of production costs and tax per unit sold multiplied by the number of units sold:

$$
\begin{aligned}
\text { Cost } & =(\text { cost of production per unit }+ \text { tax per unit }) \times \text { number of units sold } \\
& =(6.50+2) \times \text { number of units sold } \\
& =8.50 \times \text { number of units sold }
\end{aligned}
$$

- So:

$$
\begin{aligned}
& \text { Seller's profit } \\
& \quad=(\text { sales revenue })-(\text { cost }) \\
& =(\text { price } \times \text { number of units sold })-(8.50 \times \text { number of units sold }) \\
& =(\text { price }-8.50) \times \text { number of units sold }
\end{aligned}
$$

- Please note that a seller will make a loss if he/she sells the units at a price lower than the total sum of the costs and tax per unit (i.e., 8.50 Talers).

- There will be four sellers in each market. At the beginning of the experiment, four participants will be randomly assigned to a market as sellers, and these sellers will remain as sellers in this market in all rounds of the two parts of the experiment.

- At the beginning of each round, all the sellers of a market will simultaneously and independently choose a selling price. The prices are then recorded and compared. Only the lowest of the prices chosen by the sellers will be presented to the buyers, who then have to decide whether or not to buy at this price. This means that only the seller with the lowest price can sell his units (up to four) on the market. If more than one seller chooses this lowest price, the units to be sold will be evenly divided between these sellers.

\section{Buyers}

- Each buyer can buy exactly one unit on the market. The value of a unit bought is 24.50 Talers for each buyer. (The value is determined by the fact that the laboratory pays exactly this price to the buyers for each unit bought.)

- If a buyer purchases one unit of the product, the buyer's profit per round is the difference between the unit value and the purchase price:

$$
\text { Buyer's profit }=\text { value }- \text { price }=24.50-\text { price }
$$

- There will be four buyers in each market. This means, the maximum demand in a market is four units.

- At the beginning of the experiment, four participants will be randomly assigned as buyers and will then remain buyers in this market in all rounds of the two parts of the experiment. 
- Once the sellers have simultaneously and independently chosen their selling price at the beginning of a round, the lowest of the four prices will be selected and presented to the buyers. The buyers then have to decide whether or not to buy at this price.

- If a buyer does not want to buy a unit at that price, he or she may press the push-button specifying "Do not Buy".

- If a buyer wants to buy a unit at that price, he or she can press the push-button indicating "Buy at this price".

- Please note that a buyer will make a loss if he/she buys a unit at a price that is higher than the value of a unit (i.e. higher than 24.50 Talers).

\section{Sequence of actions in the experiment}

- Each market consists of four sellers (who can each sell up to four units of the product) and four buyers (who can each purchase one unit). At the beginning of the experiment participants will be informed as to whether they are a seller or a buyer. The first phase of the experiment consists of 10 rounds. The sequence of a round in the first phase is as follows:

- At the beginning of each round, the sellers of a market independently choose a price at which they are obligated, depending on the demand, to sell four units. For this purpose, each seller chooses a non-negative integer $(0,1,2,3 \ldots)$ as a price, and confirms this by pressing the "OK" button.

- The lowest of the prices chosen by the sellers will then be displayed to the buyers. Each buyer then has to independently decide whether or not to buy a unit of the product at the given price.

- To summarize the information in each round, the computer will then reveal the following information:

- Seller: own chosen price, the lowest price chosen, the number of own units sold and the own profit.

- Buyer: Lowest price chosen and own profit. 


\section{Instructions for the BertSim treatment}

\section{Welcome to this experiment!}

\section{General Information}

- Please read these instructions carefully and completely.

- Please do not talk to your neighbors and keep quiet during the entire experiment.

- Raise your hand if you have a question. One of us will come to you.

- All participants in the experiment have been given the same instructions.

\section{Introduction}

- In this experiment you will repeatedly make decisions. By doing so you can earn money.

- Your gains are measured in Talers. How much you earn depends on your decisions and the decision of other participants.

- At the beginning of the experiment, each participant will receive an initial endowment of 25 Talers.

- At the end of the experiment your total sum of Talers will be determined by the sum of the initial endowment plus the number of Talers you have earned in each round.

- At the end of the experiment you will receive 1 euro in cash for every 10 Talers. In addition, each participant will receive a participation fee of 4 euros.

- During the entire experiment, anonymity among participants and instructors will be kept.

- The experiment consists of two parts, each of which consists of 10 rounds. The rules for the first part will be explained now. The rules for the second part will be given after completion of the first part of the experiment.

\section{Description of the experiment}

- In this experiment you will act in a market in which there are sellers on one side and buyers on the other side of the market. In the following we will describe both sides of the market.

\section{Sellers}

- Sellers represent firms that manufacture and sell a product in this market. Each seller may sell up to four units of the product on the market. The production cost per unit sold is 6.50 Talers. In addition, each seller has to pay a tax of 2 Talers for each unit sold.

- In every round, each seller chooses the price at which he/she wishes to sell the product. This price must be a non-negative integer $(0,1,2,3 \ldots)$. By opting for this price, the seller declares that he/she wishes to sell up to four units of the product at this price.

- The seller's profit per round is calculated by the difference between the sales revenue and the cost: 
Seller's profit $=$ sales revenue - cost

- The sales revenue is equal to the chosen price multiplied by the number of units sold:

Sales revenue $=$ price $\times$ number of units sold

- The costs incurred are equal to the sum of production costs and tax per unit sold multiplied by the number of units sold:

$$
\begin{aligned}
\text { Cost } & =(\text { cost of production per unit }+ \text { tax per unit }) \times \text { number of units sold } \\
& =(6.50+2) \times \text { number of units sold } \\
& =8.50 \times \text { number of units sold }
\end{aligned}
$$

- So:

$$
\begin{aligned}
& \text { Seller's profit } \\
& \quad=(\text { sales revenue })-(\text { cost }) \\
& =(\text { price } \times \text { number of units sold })-(8.50 \times \text { number of units sold }) \\
& =(\text { price }-8.50) \times \text { number of units sold }
\end{aligned}
$$

- Please note that a seller will make a loss if he sells the units at a price lower than the total sum of the costs and tax per unit (i.e., 8.50 Talers).

- There will be exactly four sellers in each market. At the beginning of the experiment, four participants will be randomly assigned to a market as sellers, and these sellers will remain as sellers in this market in all rounds of the two parts of the experiment.

- At the beginning of each round, all the sellers of a market will simultaneously and independently choose a selling price. The prices are then recorded and compared. Only the lowest of the prices chosen by the sellers will be presented to the buyers, who then have to decide whether or not to buy at this price. This means that only the seller with the lowest price can sell his units (up to four) on the market. If more than one seller chooses this lowest price, the units to be sold will be evenly divided between these sellers.

\section{Buyers}

- Each buyer can buy exactly one unit on the market. The value of a unit bought is 24.50 Talers for each buyer. (The value is determined by the fact that the laboratory pays exactly this price to the buyers for each unit bought.)

- If a buyer purchases one unit of the product, the buyer's profit per round is the difference between the unit value and the purchase price:

$$
\text { Buyer's profit }=\text { value }- \text { price }=24.50-\text { price }
$$

- There will be four buyers in each market. This means, the maximum demand in a market is four units.

- There are no real buyers in this experiment. Instead, the buyers in all rounds of the two parts of the experiment are simulated by the computer. There are four computer-simulated buyers. 
- Once the sellers have simultaneously and independently chosen their selling price at the beginning of a round, the lowest of the four prices will be selected and presented to the buyers. The simulated buyers then have to decide whether or not to buy at this price.

- None of the simulated buyers will purchase a unit of the product if the price is higher than the 24.50 value of a unit.

- Each of the four simulated buyers will purchase one unit of the product at a price that is less than or equal to the 24.50 value of a unit.

\section{Sequence of actions in the experiment}

- Each market consists of four sellers (who can each sell up to four units of the product) and four simulated buyers (who can each purchase one unit). The first phase of the experiment consists of 10 rounds. The sequence of a round in the first phase is as follows:

- At the beginning of each round, the sellers of a market independently choose a price at which they are obligated, depending on the demand, to sell four units. For this purpose, each seller chooses a non-negative integer $(0,1,2,3 \ldots)$ as a price, and confirms this by pressing the "OK" button.

- The lowest of the prices chosen by the sellers will then be displayed to the buyers. Each buyer then has to independently decide whether or not to buy a unit of the product at the given price.

- To summarize the information in each round, the computer will then reveal the following information:

- Own chosen price, the lowest price chosen, the number of own units sold and own profit. 